\title{
Beyond and Before: Progressive Rock since the 1960s
}

Paul Hegarty and Martin Halliwell

New York: Continuum Books, 2011

ISBN: 9780826423320 (PB)

RRP: \$24.95 (USD)

\author{
Michael Kaler \\ York University, Canada \\ mkaler@york.ca
}

This publication gives Paul Hegarty and Martin Halliwell an opportunity to share their love - and their understanding - of progressive rock with their readers; exposing the broad outlines of the genre from its inception in the psychedelic era, through its alleged death at the hands of punk, to its descent underground in the 1980s and its slow mutation and eventual re-emergence. Yet, despite what its title may suggest, it is neither a complete history of progressive rock nor a textbook, as the authors do not offer a ready-made definition of the genre, wishing instead to maintain a "highly diverse and open-ended idea of what progressive rock is" (p. 4) - a sensible choice.

Fourteen chapters offer examinations of a series of topics - prog's roots; its politics; "the female voice"; its interactions with folk and jazz music - but overall it becomes apparent that for Hegarty and Halliwell, prog is to be understood dialogically, through its relations with other genres of rock. To begin with, there is its older sibling, psychedelia, a beloved family member who is presented as being adventurous but also unfocused and prone to rambling - obviously a bit of a pot-head, unlike its imaginative but disciplined younger brother prog.

Psychedelia celebrates "the experience of sensual absorption: it offers a total experience for the listener, but often at the expense of the contemplative and cerebral spaces that would characterize progressive rock" (p. 34). Progressive rock picks up on many of the new aesthetic and sonic potentials opened up by psychedelia, but allies them with a love of elaborated structure and an appreciation for the work of art as a separated aesthetic fact, rather than as something for the listener to immerse herself in. In fact, there was a lot more going on, cerebrally as well as bodily, with psychedelic experimentation than Hegarty and Halliwell give credit for. However, their description certainly does ground prog's indubitable love for sheer spectacle, whether on stage, on album jackets, or in elaborately constructed and mythologically-influenced song cycles, all topics dealt with in chapters of their own.

With regard to punk rock, prog's 'Great Enemy', Hegarty and Halliwell address the antipathy between the two genres, and suggestively link the effectiveness of the punkera critique of prog to the rise in status of the rock journalists in the mid-1970s, leading to "position-taking and a pressure to progress" (p. 165) - ironically, to progress beyond prog. This is no doubt true, although greater consideration of the North American 
critical take on punk would have enabled the authors to nuance their analysis, and would also have given them an opportunity to address the crucial issue of authenticity, a concept of great importance for an understanding of prog and its critical reception. There is a great deal of difference between the goals and approaches of Public Image Limited and those of Television, two bands discussed side by side in the punk rock chapter, for instance - indeed, one of the few things they have in common is that neither of them would be considered punk according to current definitions of the word.

Nonetheless, the book correctly highlights the exaggerated nature of reports of prog's demise in the punk era, and to point to post-punk as having particular importance for its future developments as it enters the 1980s, an era of confusion and retrenchment for prog. It is a great virtue of this book that a full third of it is devoted to prog's adventures after punk rock, discussing the rise of neo-prog, music that works with and within prog's standards as set in the genre's glory days, including groups such as Marillion or Pendragon; post-prog, which the authors cleverly define as "progressive rock that stems from sources other than progressive rock" (p. 124), including such bands as Talk Talk and Radiohead; and the re-emergence of progressive folk and its mingling with prog. As this part of the book develops, the reader becomes aware of the overriding importance of various forms of metal for prog's development in the 1990s and 2000s.

Metal, it is clear, is prog's third generic dialogue partner: prog evolved out of psychedelia, was challenged by punk and set to wandering in the wilderness, and has now found a new home with metal. It is difficult to argue with the authors' conclusion that "metal in its many guises" is "the location of authentic progressive rock of the 2000 s" (p. 279), and the book shows this through its very brief illustration of the way that heavy metal virtuosity evolved into a fertile ground for prog-style music-making through its interaction with hardcore aesthetics, followed by discussion of prog-allied metal bands. Hegarty and Halliwell argue that "fusion of styles is what makes a metal band progressive" (p. 279): it is interesting to think with the authors about the various ways in which the bands that are mentioned - including Opeth, Tool, and Dream Theater - navigate those fusions, especially with prog itself being one of the styles drawn upon.

The book is engaging and worthwhile, but it does have some flaws, which restrict its usefulness. There are, for example, a number of factual errors. For instance, while the authors' assumption that the Grateful Dead's first album was "country rock" (p. 40; they were probably thinking of the band's 5th and 6th albums) is not crucial, errors such as this give the impression that the book was written hurriedly. More broadly, the authors tend to make sweeping interpretive statements without adequate (or, often, any) exterior support. How do they know, for example, that Television's "Marquee Moon" is "a response to punk as much as to bloated rock music" (p. 170)? When they write that heavy metal percussion "took off from the polyrhythmic jazz drumming of Elvin Jones" (p. 259), I begin to question their knowledge of Bill Ward's work - to say nothing of Lars Ulrich!

All in all, I found this book to be a stimulating, if at times exasperating, voyage through prog rock, with two knowledgeable, passionate, and extremely opinionated guides. It is a voyage worth taking for those with some degree of familiarity with prog rock and rock in general. 


\title{
Beyond and Before: Progressive Rock since the 1960s
}

Paul Hegarty and Martin Halliwell

New York: Continuum Books, 2011

ISBN: 9780826423320 (PB)

RRP: \$24.95 (USD)

\author{
Michael Kaler \\ York University, Canada \\ mkaler@york.ca
}

This publication gives Paul Hegarty and Martin Halliwell an opportunity to share their love - and their understanding - of progressive rock with their readers; exposing the broad outlines of the genre from its inception in the psychedelic era, through its alleged death at the hands of punk, to its descent underground in the 1980s and its slow mutation and eventual re-emergence. Yet, despite what its title may suggest, it is neither a complete history of progressive rock nor a textbook, as the authors do not offer a ready-made definition of the genre, wishing instead to maintain a "highly diverse and open-ended idea of what progressive rock is" (p. 4) - a sensible choice.

Fourteen chapters offer examinations of a series of topics - prog's roots; its politics; "the female voice"; its interactions with folk and jazz music - but overall it becomes apparent that for Hegarty and Halliwell, prog is to be understood dialogically, through its relations with other genres of rock. To begin with, there is its older sibling, psychedelia, a beloved family member who is presented as being adventurous but also unfocused and prone to rambling - obviously a bit of a pot-head, unlike its imaginative but disciplined younger brother prog.

Psychedelia celebrates "the experience of sensual absorption: it offers a total experience for the listener, but often at the expense of the contemplative and cerebral spaces that would characterize progressive rock" (p. 34). Progressive rock picks up on many of the new aesthetic and sonic potentials opened up by psychedelia, but allies them with a love of elaborated structure and an appreciation for the work of art as a separated aesthetic fact, rather than as something for the listener to immerse herself in. In fact, there was a lot more going on, cerebrally as well as bodily, with psychedelic experimentation than Hegarty and Halliwell give credit for. However, their description certainly does ground prog's indubitable love for sheer spectacle, whether on stage, on album jackets, or in elaborately constructed and mythologically-influenced song cycles, all topics dealt with in chapters of their own.

With regard to punk rock, prog's 'Great Enemy', Hegarty and Halliwell address the antipathy between the two genres, and suggestively link the effectiveness of the punkera critique of prog to the rise in status of the rock journalists in the mid-1970s, leading to "position-taking and a pressure to progress" (p. 165) - ironically, to progress beyond prog. This is no doubt true, although greater consideration of the North American 
critical take on punk would have enabled the authors to nuance their analysis, and would also have given them an opportunity to address the crucial issue of authenticity, a concept of great importance for an understanding of prog and its critical reception. There is a great deal of difference between the goals and approaches of Public Image Limited and those of Television, two bands discussed side by side in the punk rock chapter, for instance - indeed, one of the few things they have in common is that neither of them would be considered punk according to current definitions of the word.

Nonetheless, the book correctly highlights the exaggerated nature of reports of prog's demise in the punk era, and to point to post-punk as having particular importance for its future developments as it enters the 1980s, an era of confusion and retrenchment for prog. It is a great virtue of this book that a full third of it is devoted to prog's adventures after punk rock, discussing the rise of neo-prog, music that works with and within prog's standards as set in the genre's glory days, including groups such as Marillion or Pendragon; post-prog, which the authors cleverly define as "progressive rock that stems from sources other than progressive rock" (p. 124), including such bands as Talk Talk and Radiohead; and the re-emergence of progressive folk and its mingling with prog. As this part of the book develops, the reader becomes aware of the overriding importance of various forms of metal for prog's development in the 1990s and 2000s.

Metal, it is clear, is prog's third generic dialogue partner: prog evolved out of psychedelia, was challenged by punk and set to wandering in the wilderness, and has now found a new home with metal. It is difficult to argue with the authors' conclusion that "metal in its many guises" is "the location of authentic progressive rock of the 2000 s" (p. 279), and the book shows this through its very brief illustration of the way that heavy metal virtuosity evolved into a fertile ground for prog-style music-making through its interaction with hardcore aesthetics, followed by discussion of prog-allied metal bands. Hegarty and Halliwell argue that "fusion of styles is what makes a metal band progressive" (p. 279): it is interesting to think with the authors about the various ways in which the bands that are mentioned - including Opeth, Tool, and Dream Theater - navigate those fusions, especially with prog itself being one of the styles drawn upon.

The book is engaging and worthwhile, but it does have some flaws, which restrict its usefulness. There are, for example, a number of factual errors. For instance, while the authors' assumption that the Grateful Dead's first album was "country rock" (p. 40; they were probably thinking of the band's 5th and 6th albums) is not crucial, errors such as this give the impression that the book was written hurriedly. More broadly, the authors tend to make sweeping interpretive statements without adequate (or, often, any) exterior support. How do they know, for example, that Television's "Marquee Moon" is "a response to punk as much as to bloated rock music" (p. 170)? When they write that heavy metal percussion "took off from the polyrhythmic jazz drumming of Elvin Jones" (p. 259), I begin to question their knowledge of Bill Ward's work - to say nothing of Lars Ulrich!

All in all, I found this book to be a stimulating, if at times exasperating, voyage through prog rock, with two knowledgeable, passionate, and extremely opinionated guides. It is a voyage worth taking for those with some degree of familiarity with prog rock and rock in general. 